\title{
EL INTERÉS FAMILIAR Y SU RELEVANCIA JURÍDICA A PROPÓSITO DEL VIII PLENO CASATORIO
}

\section{THE FAMILY INTEREST AND ITS LEGAL RELEVANCE FOR THE PURPOSE OF THE VIII PLENARY CASATORY}

* Maestría en Derecho Civil y Comercial y Abogado por la UNMSM. Amplia experiencia en procesos judiciales referidos a Derecho de Familia y Sucesiones. Socio Fundador del estudio especializado en Derecho de Familia y Sucesiones, "Del Aguila Llanos Abogados S.A.C." Consultor contratado por el Ministerio de la Mujer (2016). Autor de los libros "Guía práctica de derecho de alimentos" (año 2015), "Comentarios a la ley 30364 y su reglamento" (año 2019) y "Patria Potestad, Tenencia y Régimen de Visitas. Doctrina y Jurisprudencia" (año 2019). Autor de diversos artículos en Derecho de Familia y Sucesiones en diversas revistas a nivel nacional. Docente exclusivo de LP - Pasión por el Derecho.

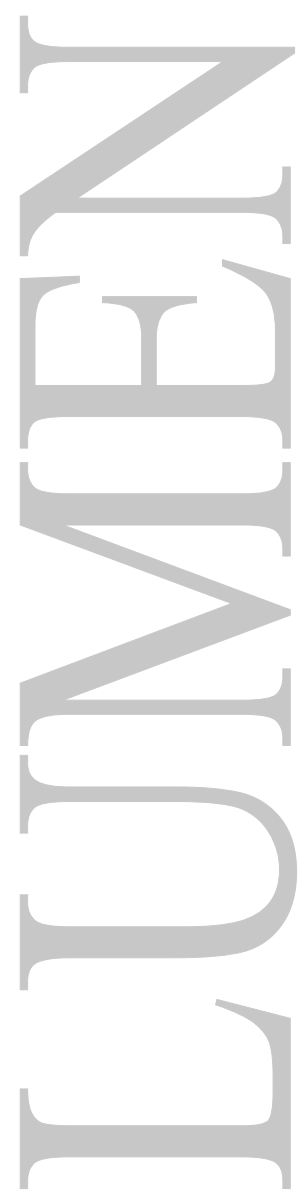




\title{
EL INTERÉS FAMILIAR Y SU RELEVANCIA JURÍDICA A PROPÓSITO DEL VIII PLENO CASATORIO
}

\author{
THE FAMILY INTEREST AND ITS LEGAL RELEVANCE FOR THE \\ PURPOSE OF THE VIII PLENARY CASATORY
}

Del Aguila Llanos, Juan Carlos

\begin{abstract}
RESUMEN:
El autor analiza la importancia de recordar la existencia de los intereses dentro de la familia como base para resolver los diversos conflictos que puedan acontecer dentro del marco de las relaciones familiares e inclusive para enfrentar los vacíos legales que puedan existir en la normativa que regula estas relaciones familiares, pues considera que debe aplicarse una interpretación sistemática de la norma especializada, respetándose la particularidad del Derecho de Familia, dejándose el pensamiento de que todo debe ser resuelto solo observando criterios aplicables a normas generales del Derecho Civil. Este tema es abordado a partir de la decisión adoptada en mayoría en el VIII octavo pleno casatorio civil que determinó que la no intervención de ambos cónyuges en la disposición de un bien social es nulo.
\end{abstract}

\section{PALABRAS CLAVES:}

Interés familiar, Interés del niño, Pleno casatorio civil.

\begin{abstract}
:
The author analyzes the importance of remembering the existence of interests within the family as a basis to resolve the various conflicts that may occur within the framework of family relationships and even to face the legal gaps that may exist in the regulations that regulate these relationships relatives, as it considers that a systematic interpretation of the specialized norm should be applied, respecting the particularity of Family Law, leaving behind the thought that everything should be resolved only by observing criteria applicable to general norms of Civil Law. This issue is approached from the decision adopted by a majority in the eighth eighth plenary session civil which determined that the non-intervention of both spouses in the provision of a social good is null.
\end{abstract}

\section{KEY WORDS:}

Family interest, Interest of de child, full civil casatorio

\section{A MANERA DE INTRODUCCIÓN}

Durante mucho tiempo, el $315^{\circ}$ del código civil, ha venido siendo materia de múltiples análisis, toda vez que no se precisaba si la consecuencia jurídica de la disposición unilateral de un bien social, generaba la ineficacia estructural (nulidad) o ineficacia funcional (ineficacia) del acto jurídico celebrado.

Como consecuencia de esta situación, los jueces a nivel nacional no tenían un criterio claro de cómo resolver las demandas que aludían a estas disposiciones unilaterales y, por tanto, la toma de decisión dependía estrictamente de sus criterios personales y en consecuencia, era el aspecto subjetivo lo que definía todo.

Esta situación se mantuvo hasta el presente año, toda vez que después de una larga espera, fue emitido el VIII Pleno Casatorio Civil, el cual, mediante un fallo en mayoría, procede a indicar que la consecuencia jurídica ante los actos de disposiciones de bienes sociales en forma unilateral, son considerados nulos. 
El fundamento de la decisión adoptada por la Corte Suprema, es que debe respetarse el interés familiar y, en consecuencia, no debe permitirse que uno de los cónyuges tome decisiones a espaldas del otro para perjudicarlo y se acepte que disponga bienes en forma indebida.

Muchos discrepan de la decisión adoptada por el VIII Pleno Casatorio debido a que considera que se está perjudicando al tráfico de bienes en el mercado y sobre todo, al adquiriente de los bienes. Sin embargo, no se realiza un análisis respecto del que fuera precisamente el fundamento del pleno: el interés familiar.

En ese sentido, consideramos necesario, realizar el presente artículo a efectos de que observe precisamente a qué se hace referencia cuando se trata de interés familiar y se pueda comprender del porqué de la necesidad de su protección por los jueces a nivel nacional. Espero nos puedan acompañar en el análisis.

\section{LA FAMILIA}

El Tribunal Constitucional en los últimos años viene actuando como el principal centro de análisis de las relaciones jurídicas familiares que no encuentran solución efectiva en la normativa actual.

Así tenemos que la Sentencia emitida por el Tribunal Constitucional en el expediente N $.^{\circ} 06572-$ 2006-PA/TC, se establece que:

“(...) el texto constitucional no pretendió reconocer un modelo específico de familia. (....) Los cambios sociales generados a lo largo del siglo XX han puesto el concepto tradicional de familia en una situación de tensión y es que al ser éste un instituto ético-social, se encuentra inevitablemente a merced de los nuevos contextos sociales. Por lo tanto, hechos como la inclusión social y laboral de la mujer, la regulación del divorcio y su alto grado de incidencia, las migraciones hacia las ciudades, entre otros aspectos, han significado un cambio en la estructura de la familia tradicional nuclear, conformada alrededor de la figura del pater familias. Consecuencia de ello es que se hayan generado familias con estructuras distintas a la tradicional como son las surgidas de las uniones de hecho, las monopaternales o las que en doctrina se han denominado familias reconstituidas. Bajo esta perspectiva, la familia no puede concebirse únicamente como una institución en cuyo seno se materialice la dimensión generativa o de procreación únicamente. (...) No podrá argumentarse, en consecuencia, que el Estado solo tutela a la familia matrimonial, tomando en cuenta que existen una gran cantidad de familias extramatrimoniales. Es decir, se comprende que el instituto familia trasciende al del matrimonio, pudiendo darse la situación de que extinguido este persista aquella (...).

Otra sentencia también nos parece interesante compartir, como lo es la que recaída sobre el expediente $\mathrm{N}^{\circ}$ 09332-2006-PA/TC, en donde se precisa que:

"Las relaciones entre padrastros o madrastras y los hijastros/as deben ser observadas de acuerdo con los matices que el propio contexto impone. (...) Es de indicar que la situación jurídica del hijastro no ha sido tratada por el ordenamiento jurídico nacional de forma explícita, ni tampoco ha sido recogida por la jurisprudencia nacional. No obstante, sobre la base de lo expuesto queda establecido que el hijastro forma parte de esta nueva estructura familiar, con eventuales derechos y deberes especiales, no obstante la patria potestad de los padres biológicos. No reconocer ello traería aparejada una afectación a la identidad de este nuevo núcleo familiar, lo que de hecho contraría lo dispuesto en la carta fundamental respecto de la protección que merece la familia como instituto jurídico constitucionalmente garantizado. Desde luego, la relación entre los padres afines y el hijastro tendrá que guardar ciertas características, tales como las de habitar y compartir vida de familia con cierta estabilidad, 
publicidad y reconocimiento. Es decir, tiene que reconocerse una identidad familiar autónoma, sobre todo si se trata de menores de edad que dependen económicamente del padre o madre afín. De otro lado, si es que el padre o madre biológica se encuentran con vida, cumpliendo con sus deberes inherentes ello no implicará de ninguna manera la pérdida de la patria potestad"

Se amplía en ese sentido, el concepto de familia a las diferentes manifestaciones de ella en la sociedad, más aún cuando la Constitución de 1993 reconoce la necesidad de proteger a la familia sin importar si esta surge como consecuencia de una relación sexual acontecida dentro del matrimonio o fuera del matrimonio, apartándose así de la posición que era albergada por la anterior Constitución de 1979.

El reconocimiento de la afectividad entre los miembros de la familia, hace que el alcance de protección reconocido por la Constitución se amplíe año tras año a pasos agigantados y este hecho no es dejado de ser observado por el Tribunal Constitucional.

El profesor Benjamín Aguilar Llanos, tratando sobre temas familiares, señala que "conocido es que las familias peruanas no tienen como único origen el matrimonio, en tanto que familia se origina igualmente en las uniones de hecho, que sin haber pasado por el registro civil constituyen familias cumpliendo con todas responsabilidades que se dan en las familias matrimoniales. Asimismo, es de conocimiento público que la Constitución establece el deber del Estado de proteger a las familias" (AGUILAR, 2017; p. 92 - 93).

Por otro lado, Alejandro Cussiaovich Villarán, al respecto de la familia precisa que "(...) la familia es el lugar natural de acogimiento de un ser humano, cualquier sea la estructura de la familia que imaginemos o que se tenga en una sociedad y por tanto, es el lugar llamado a garantizar la sobrevivencia inicial del ser humano nacido vivo, de brindarle no solo sobrevivencia física, sino emocional, afectiva, lecho de atención, de protección, de provisión, de estímulo (...)" (CUSSIANOVICH, 2007: p. 50-51)

En las posiciones de los autores señalados se observa que el aspecto en que coinciden es en resaltar que las familias tienen como base esencial la unión afectiva que debe unir a sus miembros y de allí que sin importar la fuente que las genera, deberá comprender como miembros de una familia a todos aquellos que socio afectivamente desean comportarse como tal.

Puede sonar un tanto gaseoso estas posiciones, sin embargo, los autores precisados reconocen el alto valor emocional que se encuentra albergado en la idea de "familia".

Conforme estamos observando no existe realmente un concepto de familia uniforme o claro, sin embargo, nosotros consideramos que sin importar el concepto social que se le desee otorgar, el cual ya hemos resaltado en la doctrina y en la propia posición del Tribunal Constitucional, lo relevante siempre será el contenido legal que se le otorgue porque será este contenido el que pueda tener relevancia en las diferentes relaciones jurídicas que se presenten.

En ese sentido, en nuestra opinión, debe entenderse que el concepto de familia abarca a todas aquellas personas cuyas situaciones jurídicas se encuentran unidas por un vínculo que el Derecho de Familia reconoce como vínculo familiar.

El primer caso donde observamos que se regula la existencia de este vínculo familiar, es en el caso plasmado en los artículos 236, 237 y 238 del código civil en donde se reconoce el parentesco por consanguinidad, afinidad y por adopción respectivamente, los cuales generan un vínculo reconocido en las diferentes instituciones reguladas dentro del libro correspondiente al Derecho de Familia en el Código Civil. 
Así tenemos que el citado vínculo se reconoce en los impedimentos para casarse; impedimentos para ser testigos de un testamento o para ser el notario encargado de observar su elaboración; llamamiento a ser tutores o curadores de una persona; derecho a visitar a un menor de edad; la conformación del propio consejo de familia; entre otros.

El segundo caso, lo encontramos en la ley 30364 - Ley para prevenir, sancionar y erradicar la violencia contra las mujeres y los integrantes del grupo familiar - en el cual amplía un tanto más el citado vínculo familiar reconocido por el código civil, al señalarse en el artículo $7^{\circ}$ de la citada ley especial, que un sujeto de protección son los integrantes del grupo familiar, considerando que el vínculo de afinidad y consanguinidad antes precisado es solo un pequeño subgrupo dentro del grupo mayor denominado integrantes del grupo familiar entre los que podemos encontrar a los convivientes, padrastros, madrastras, ex convivientes, ex cónyuges, entre otros que normalmente no consideraríamos usualmente como familia (piénsese por ejemplo en aquel menor que vive en nuestra casa sin tener un contrato laboral o comercial que lo obligue a vivir con nosotros y además que no tiene vínculo por adopción, consanguíneo o afinidad)

Comprendemos que el concepto de familia es muy amplio como para que una norma lo pueda definir, pero también consideramos necesario siempre observar los efectos que las normas especiales reconocen a las personas que la conforman porque caso contrario, estaríamos considerando que cualquier persona pueda ser considerada como miembro de nuestra familia cuando en realidad no tiene relevancia jurídica dichas relaciones interpersonales desde un punto de vista estrictamente familiar.

\section{INTERESES DENTRO DE LA FAMILIA}

Uno de los principales intereses reconocido dentro del ámbito familiar, es precisamente el Interés Superior del Niño, recogido en nuestra legislación en el artículo IX del Título Preliminar del Código de los Niños y Adolescentes.

Respecto del "interés superior del niño, niña y adolescente", la doctora Ana Cecilia Garay Molina señala que "debe concebirse necesariamente como la búsqueda de la satisfacción de los derechos fundamentales del niño o niña y nunca se puede aducir un interés de otro tipo como superior a la vigencia efectiva de estos derechos, evitando que criterios corporativistas o de supervivencia institucional, sean situados por sobre el interés superior del niño o niña" (GARAY, 2009: p. 130).

Por su parte, el doctor Víctor Montoya precisa que "el niño, niña o el adolescente, por su especial situación y por encontrarse en una posición de desventaja respecto de los llamados a velar por su protección, deben contar con una legislación y una situación acorde con sus necesidades que a su vez, requieren un ejercicio pleno de los derechos que la constitución le ofrece" (MONTOYA, 2007: p. 50).

Así también, el Doctor Alex Plácido Vilcachagua, respecto de los intereses de los niños, niñas y adolescentes, resalta que "el deber de considerar su interés superior se impone como el criterio que deben seguir sus padres o responsables en el cuidado de su persona y bienes y que ha de tener en cuenta el juez de familiar para salvaguardar su integridad y tutelar in extenso de sus derechos específicos" (PLÁCIDO, 2002: p. 34).

Adicionalmente al interés superior del niño, se observa el denominado interés familiar. Para reconocerlo basta tener en cuenta que en el libro III del código civil, se regula las diversas situaciones que pueden acontecer entre los miembros de una familia. Precisamente en el primer artículo del citado Libro, encontramos al artículo 233 del código civil, el cual establece que las relaciones jurídicas familiares, tienen por objetivo contribuir su consolidación y fortalecimiento. 
Combinando precisamente lo que tanto el Tribunal Constitucional como la doctrina señala considera como familia y comparándola con nuestra posición ligada a los efectos jurídicos que puedan surgir, debe comprenderse que lo que pretende la normativa es precisamente recordar a los miembros que la conforman, que se desea que entre ellos siempre exista una cordial relación y por tanto, en el hipotético caso que esto no suceda, las consecuencias jurídicas de alguna disposición normativa dentro del citado libro III del código civil, serán aplicadas para evitar que la armonía en la familia llegue a quebrarse.

Recordemos que todo sistema normativo debe ser entendido como un todo, existiendo lo que se conoce como interpretación sistemática de la ley, no debiendo observarse la normativa como aisladas sino como parte de una estructura. De allí que, esta armonía que pretende el primer artículo del Libro de Familia, alcanzará a todos los artículos que posteriormente se observarán en el Libro III del código civil.

\section{EL ARTÍCULO 315 DEL CÓDIGO CIVIL Y EL INTERÉS FAMILIAR}

El artículo $315^{\circ}$ del Código Civil, establece que para disponer bienes sociales se requiere la intervención del marido y la mujer. Sin embargo, no se señaló, conforme lo habíamos indicando anteriormente, una consecuencia jurídica ante el incumplimiento de una concurrencia de voluntades del marido y la mujer en el acto de disposición.

Para diversos juristas, se consideró que esta omisión por parte de la normativa, debía ser cubierta por la doctrina, quiénes deberían tomar una postura que genere un mayor beneficio conforme al criterio del juzgador. Sin embargo, se olvida precisamente que el artículo $315^{\circ}$ del Código Civil, forma parte del Libro III del código civil referido al Derecho de Familia y, por tanto, debería siempre apuntarse a la toma de una decisión que vaya de la mano con la armonía familiar y no a decisiones que lo que busquen es favorecer a cualquier persona menos a la familia.

Si se hubiese tenido en cuenta este claro objetivo de las normas del derecho de familia, no hubiera sido ni siquiera necesario acudir a la Corte Suprema para que adopte una posición respecto de la omisión normativa alegada por diversos juristas en el artículo $315^{\circ}$ del código civil, toda vez que de la propia normativa y de los fines del derecho de familia, se podría claramente resolver que ante la "omisión normativa" debería siempre apuntarse a evitarse cualquier situación que quiebre esta armonía y por tanto, no podría ni pensarse en mantenerse vigente los actos de disposición donde ambos cónyuges no hayan intervenido.

\section{A MANERA DE CIERRE}

Se considera que todo debe resolverse siempre basado en principios que engloban al Derecho Civil, sin embargo, debe comprenderse que el Derecho de Familia tiene una clara particularidad que lo distingue de los demás ámbitos en el Derecho Civil: El interés familiar.

La situación plasmada permite verificar que el Derecho de Familia alberga un alto contenido emocional y moral, lo cual, de seguirse una interpretación que tenga en cuenta estos contenidos, cualquier vacío en la normatividad, podría verse sencillamente superado, pues se comprenderá que todo deberá ser resuelto en función del interés familiar.

Esperamos haber aportado en el reconocimiento de este interés y en la necesidad de distinguir las situaciones que se pretenden en la vida diaria, destacando la situación especial en que se encuentran las relaciones familiares. 


\section{REFERENCIAS}

- AGUILAR LLANOS, Benjamín (2017). Matrimonio y filiación. Aspectos Patrimoniales. Lima: Gaceta Jurídica.

- CUSSIANOVICH VILLARÁN, Alejandro. "Violencia social, violencia intrafamiliar y sus implicancias para la salud mental y la administración de justicia desde el enfoque de los derechos humanos". En: Políticas sociales y violencia intrafamiliar. Lima: Poder Judicial, 2007. Pág. $50-51$.

- GARAY MOLINA, Ana Cecilia (2009). Custodia de los hijos cuando se da fin al matrimonio. Lima: Grijley.

- MONTOYA CHAVEZ, Victor Hugo (2007). Derechos fundamentales de los niños y adolescentes. El interés superior del niño y adolescente y la situación de abandono en el artículo 4 de la constitución. Lima: Grijley.

- PLACIDO V. Alex (2002). Manual de derecho de familia. Lima: Gaceta Jurídica.

Fecha de recepción: 23 de octubre de 2020

Fecha de aceptación:06 de noviembre de 2020 